\title{
Factor analysis of the clustering of common somatic symptoms: a preliminary study
}

\author{
Chung-Huang Tsai $1,2,3$
}

\begin{abstract}
Background: Studies of outpatient department patients indicate that somatic discomforts such as headache, neck pain, chest pain, low back pain, and gastrointestinal discomfort are commonly found in patients with multiple complaints. Clustering of some symptoms has been found in common somatic symptom analyses. Because of the complexity involved in the diagnosis of patients with multiple complaints, the aim of this study is to identify and classify patterns of somatic symptoms in individuals assessed during a health examination.

Methods: A total of 683 patients (437 males, 246 females) received a one-day physical examination and completed a structured survey during the period from May 2007 to April 2008. A physical symptoms interview was conducted, and medical and demographic data was collected.

Results: Based on the factor analysis, 4 clusters of symptoms were identified: 1) pain symptoms, 2) cold symptoms, 3) cardiopulmonary symptoms, and 4) gastrointestinal symptoms. The distribution of symptoms differed between males and females. After varimax rotation of factor patterns, 4 extracted factors emerged. In males, the factors were 1) pain symptoms, 2) cold symptoms, 3) cardiopulmonary symptoms, and 4) gastrointestinal symptoms. In females, the factors were 1) pain symptoms, 2) cold symptoms, 3) cardiopulmonary symptoms, and 4) head and gastrointestinal symptoms.

Conclusions: Four clusters of somatic symptoms emerged for both males and females; however, the predominant symptoms were different in males and females. Females displayed more head-related symptoms than males. Patients should be thoroughly interviewed about additional symptoms within the same cluster after the recognition of a single somatic complaint.
\end{abstract}

\section{Background}

In studies comparing Outpatient Department (OPD) patients with the general population, somatic discomforts such as dizziness/headache, neck pain, chest discomfort/ chest pain, shortness of breath, low back pain, and gastrointestinal (GI) discomfort were commonly found in patients with multiple complaints [1-6]. The clustering of some symptoms has been historically found in common somatic symptom analyses. Blackwell et al. [7] and David et al. [8] divided common symptoms into 5 major categories: gastroenterological, pain, cardiopulmonary, neurological, and reproductive. Tsai et al. [9] separated the symptoms into two key categories, pain and cardiopulmonary. Other studies have highlighted gender differences in somatic symptoms of depression [10]. Crook et

* Correspondence: m333834@yahoo.com.tw

1 Department of Family Medicine, Cheng Ching Hospital, No. $118 \mathrm{sec}$. 3 ChungKang RD. Taichung 407, Taiwan

Full list of author information is available at the end of the article al. [1] found that there were similar characteristics for pain at different sites, and that some physical illnesses are associated with a clustering of somatic symptoms. A study of an ambulatory elderly population found that patients with multiple complaints tended to have depression, and that multiple somatic symptoms are a good indicator for depression in the elderly [11].

Somatic discomforts or pains [12] caused by cancer [13] and other incurable chronic diseases often result in complications such as depression. In addition, depression often exacerbates the discomfort and pain [12]. Some studies have shown that depressive and anxiety disorders are associated with pain, palpitations, dizziness, and nausea, [14-18] which suggests that physical and mental disorders are intertwined. When dealing with somatic symptoms, not only should physical diseases be taken into consideration, but also mental illness should be considered. Thus, it is especially important for family physicians to understand the clustering of common somatic 
symptoms so that they will not be overwhelmed when dealing with the complexity of multiple complaint patients [19].

Because of the complexity involved in the diagnosis of patients with multiple complaints, the aim of this study is to identify and categorize clustering of somatic symptoms such that if a patient has one somatic symptom, other symptoms in the same cluster may be investigated in order to improve the quality and accuracy of diagnosis in a primary care setting. We believe this descriptive analysis of common somatic symptoms may provide a reference point for medical personnel to use when evaluating patients with multiple complaints.

\section{Methods}

\section{Participants}

Our study included 683 individuals who received one-day physical examinations from May 2007 to April 2008 at a regional hospital in Taichung City. The study sample was a convenience sample. The one-day physical examination is a very popular health care program in Taiwan that includes a physical examination, laboratory tests, ultrasound examination, and endoscopic examination. Physical examinations were performed by physicians of various specialties, and physicians of Family Practice Department reviewed and interpreted the final report and made health-related suggestions to the patients.

The 683 individuals completed the physical examination, associated testing, and completed interviews that recorded demographic and symptom information. Patients who were seen but could not complete the examinations or interview/survey were not considered for inclusion in the analysis. The medical ethics committee at the Cheng-Ching Hospital approved the study in May 2007. Informed consent was obtained from all participants before their participation.

\section{Study design and methods}

The symptom interview schedule was designed based on a Chinese revision of the Psychiatric Diagnostic Interview Schedule (DIS-CM) [20] that incorporated a common physical symptoms diagnostic table, foreign literature [21-23], and the study by Tsai et al. [9]. In order to find a common basis for all of the subjects, we tested 50 physical examinees. A total of 22 somatic symptoms commonly encountered during a physical examination were defined, i.e., neck pain and rigidity, lower back pain, partial somatic numbness and tingling, light-headedness, hand and foot arthralgia, muscle soreness, chest discomfort/chest pain, palpitations, poor appetite, GI discomfort, constipation/diarrhea, dizziness, headache, tinnitus, foreign bodily sensations and obstructive sensations in the throat, muscle weakness, hyperhidrosis, chill, fever, shivering, frequent micturition/nocturia ( $\geq 3$ times per night), and skin itchiness. The internal consistency reliability (Cronbach's $\alpha$ ) of the diagnostic schedule was 0.86 .

Symptoms were graded on a 5-grade scoring system; 0 represented no symptoms, and 1, 2, 3, and 4 designated mild, intermediate, severe, and very severe symptoms, respectively. Patients completed the interview/survey on the day of the physical examination prior to discussion of the results with the attending physicians. The data were input and processed in a database using the Microsoft Excel 2003.

\section{Statistical analysis}

Categorical data were presented as a number (\%), and the Chi-square test was used to test the difference between genders. The level of significance was defined as 0.05 . To reduce 22 symptoms into a smaller number of interpretable factors, exploratory factor analysis was performed.

The exploratory factor analysis was composed of 5 processes. To check the assumptions of the factor analysis, correlations among variables were examined initially. Twenty symptoms had a Pearson's correlation coefficient $>0.3$, which indicated a weak correlation between any two variables. The sampling adequacy was confirmed by an anti-image correlation matrix, the factorability was proved by a Kaiser-Meyer-Olkin index that was $>0.6$, and the result of Bartlett's test of sphericity indicated no identity matrix was present. Principal component analysis was used to extract summary factors, and only the factors with eigenvalues $\geq 1$ were extracted. The varimax rotation method was performed to simplify the interpretations of summary factors; one symptom was considered to be loaded on a factor if its factor loading was $\geq 0.50$. Finally, the name of a summary factor was denominated according to the loaded symptoms on a specific factor. All statistics were calculated with SPSS version 15.0 (SPSS Inc., Chicago, IL, USA).

\section{Results}

A total of 817 subjects received the one-day physical exam. Among them, 134 participants (16.4\%) were not included due to refusing to participate in the questionnaire or because of illiteracy. Thus, a total of 683 subjects were included in the study, 437 males and 246 females. Patient demographic data is presented in Table 1. More than half of the subjects (53.7\%) were between 45 and 64 years of age. A majority of the subjects were married (81.0\%), employed (76.6\%), and had an advanced education level (college or above) (42.8\%). When compared to females, more males were between 45 and 64 years of age (57.2\% vs. $47.5 \%, P=0.022)$, employed $(89.2 \%$ vs. $54.1 \%, P$ $<0.001)$, had a higher education level ( $48.9 \%$ vs. $32.2 \%, P$ $<0.001)$, were smokers $(40.5 \%$ vs. $6.1 \%, P<0.001)$, and consumed alcohol $(47.8 \%$ vs. $14.2 \%, P<0.001)$. 
Table 1: Patient characteristics

\begin{tabular}{|c|c|c|c|}
\hline & $\begin{array}{l}\text { Male } \\
(n=437)\end{array}$ & $\begin{array}{l}\text { Female } \\
(n=246)\end{array}$ & $P$-value1 \\
\hline Age (years) & & & $0.022^{*}$ \\
\hline$<45$ & $161(36.8)$ & $104(42.3)$ & \\
\hline $45-65$ & $250(57.2)$ & $117(47.5)$ & \\
\hline$\geq 65$ & $26(6.0)$ & $25(10.2)$ & \\
\hline Education ${ }^{2}$ & & & $<0.001^{*}$ \\
\hline Junior high school or below & $95(21.9)$ & $98(40.0)$ & \\
\hline Senior high school & $127(29.2)$ & $68(27.8)$ & \\
\hline College or above & $213(48.9)$ & $79(32.2)$ & \\
\hline Religion & & & $0.008^{*}$ \\
\hline None & $76(17.4)$ & $40(16.3)$ & \\
\hline Folk belief & $142(32.5)$ & $66(26.8)$ & \\
\hline Taoism & $75(17.1)$ & $38(15.4)$ & \\
\hline Buddhism & $131(30.0)$ & $79(32.1)$ & \\
\hline Others & $13(3.0)$ & $23(9.4)$ & \\
\hline Marital status & & & $<0.001^{*}$ \\
\hline Single & $43(9.8)$ & $20(8.1)$ & \\
\hline Married & $378(86.5)$ & $175(71.2)$ & \\
\hline Other & $16(3.7)$ & $51(20.7)$ & \\
\hline Employment & & & $<0.001^{*}$ \\
\hline Employed & $390(89.2)$ & $133(54.1)$ & \\
\hline Unemployed & $47(10.8)$ & $113(45.9)$ & \\
\hline Smokers & $177(40.5)$ & $15(6.1)$ & $<0.001^{*}$ \\
\hline Alcohol drinkers & $209(47.8)$ & $35(14.2)$ & $<0.001^{*}$ \\
\hline
\end{tabular}

Data presented as number (percent).

${ }^{1} P$-values were derived from the chi-square test.

2 Missing data was noted.

*Indicates statistical significance, $P<0.05$.

Table 2 presents the distribution of symptoms between males and females. Except for tinnitus and chest pain, which showed similar percentage of agreement among the genders, 20 out of 22 symptoms were more prevalent in females, and 10 out of those 20 symptoms, including dizziness (8.1\%), headache (8.1\%), sensation of dyspnea or asphyxia (20.4\%), palpitations $(6.0 \%)$, poor appetite (5.7\%), stomach ache or abdominal discomfort (11.0\%), constipation or diarrhea (9.7\%), low back pain (12.6\%), sensation of anesthesia (11.0\%), sensation of heavy limbs (8.6\%), joint pain (9.8\%), feeling too warm or cold (2.8\%), and frequent micturition $(8.9 \%)$ exhibited a statistically significant difference between males and females (all, $P<$ 0.05).

There were 4 factors that explained $59.1 \%$ of the total variance in the 683 subjects (Table 3). Factor 1 (pain symptoms) included neck pain, low back pain, sensation of anesthesia, sensation of heavy limbs, joint pain, muscle weakness and muscle pain, and these comprised the largest proportion (20.9\%) of the total variance. Factor 2 (cold symptoms) included cold sweating, feeling too warm or cold, shudder, and dizziness and contributed $15.2 \%$ of the total variance. Factor 3 (cardiopulmonary symptoms) included chest pain, sensation of dyspnea or asphyxia, and palpitations, and contributed $11.8 \%$ of the total variance. Factor 4 (GI symptoms) included poor appetite, stomach pain, and constipation or diarrhea, and accounted for $11.2 \%$ of the total variance. The Cronbach's $\alpha$ coefficients for Factor 1, 2, 3, and 4 were 0.861, 0.682, 0.748 , and 0.651 , respectively.

Because the distribution of symptoms for males differed significantly from that of females, further analysis by gender was performed to check whether the summary factors of both genders were different. The results pre- 
Table 2: Symptom distribution by gender

\begin{tabular}{|c|c|c|c|}
\hline & $\begin{array}{l}\text { Male } \\
(n=437)\end{array}$ & $\begin{array}{l}\text { Female } \\
(n=246)\end{array}$ & $P$-value1 \\
\hline Dizziness & $14(3.2)$ & $20(8.1)$ & $<0.001^{*}$ \\
\hline Headache & $13(3.0)$ & $20(8.1)$ & $<0.001^{*}$ \\
\hline Tinnitus & $24(5.5)$ & $13(5.3)$ & 0.850 \\
\hline Lump in throat & $22(5.0)$ & $21(8.5)$ & 0.229 \\
\hline Neck pain or stiffness & $45(10.3)$ & $42(17.1)$ & 0.061 \\
\hline Chest pain & $21(4.8)$ & $12(4.9)$ & 0.063 \\
\hline Sensation of dyspnea or asphyxia & $8(1.8)$ & $6(20.4)$ & 0.410 \\
\hline Palpitation & $12(2.8)$ & $15(6.0)$ & $0.044^{*}$ \\
\hline Poor appetite & $10(2.3)$ & $14(5.7)$ & $0.021^{*}$ \\
\hline Stomach ache or abdominal discomfort & $25(5.7)$ & $27(11.0)$ & $0.031^{*}$ \\
\hline Constipation or diarrhea & $16(3.6)$ & $24(9.7)$ & $0.001^{*}$ \\
\hline Low back pain & $44(11.1)$ & $31(12.6)$ & $0.013^{*}$ \\
\hline Sensation of anesthesia & $26(6.0)$ & $27(11.0)$ & $0.047^{*}$ \\
\hline Sensation of heavy limbs & $9(2.1)$ & $21(8.6)$ & $<0.001^{*}$ \\
\hline Joint pain & $23(5.2)$ & $24(9.8)$ & $0.004^{*}$ \\
\hline Muscle weakness & $17(3.9)$ & $17(6.9)$ & 0.155 \\
\hline Itchiness & $15(3.5)$ & $12(4.9)$ & 0.478 \\
\hline Cold sweating & $9(2.1)$ & $9(3.6)$ & 0.705 \\
\hline Feeling too warm or cold & $1(0.2)$ & $7(2.8)$ & $<0.001^{*}$ \\
\hline Shuddering & $2(0.4)$ & $4(1.6)$ & 0.422 \\
\hline Muscle pain & $25(5.7)$ & $23(9.4)$ & 0.115 \\
\hline Frequent micturition & $14(3.2)$ & $22(8.9)$ & $0.009^{*}$ \\
\hline
\end{tabular}

Data presented as number (percent).

Note: Severe and very severe symptoms were combined due to the sample size in each category.

${ }^{1}$ Chi-square test was used.

*Significantly different between genders, $P<0.05$.

sented in Table 4 and Table 5 indicated both genders exhibit 4 extracted factors. Among them, 3 common factors for both genders, pain symptoms (Factor 1), cold symptoms (Factor 2) and Factor 3 (cardiopulmonary symptoms), were found. The pain symptoms contributed $19.1 \%$ of the variance for males. For females, symptoms of exhaustion accounted for $20.1 \%$ of the variance (frequent micturition was included in this group). Regardless of gender, 3 cold symptoms were loaded on the factor called cold symptoms, which explained the $13.3 \%$ and $12.2 \%$ of the variance in males and females, respectively. Factor 3 consisted of chest pain, sensation of dyspnea or asphyxia, palpitation and frequent micturition; which explained $12.6 \%$ and $12.7 \%$ of variances in males and females. The frequent micturition was included in Factor 3 for males but it was an important component of cold symptoms for females. The Cronbach's $\alpha$ coefficient for Factor 1, Factor 2 and Factor 3 were 0.844, 0.593 and 0.698 for males, and $0.870,0.699$ and 0.749 for females, respectively.
The other summary factors for males were Factor 4 (GI symptoms) which accounted for $12.2 \%$ of the variance (Cronbach's $\alpha=0.675)$. Factor 4 consisted of all 3 digestive symptoms (Table 4). For females, Factor 4 (head and GI symptoms) consisted of head symptoms (dizziness, headache, and tinnitus) and GI symptoms (stomach pain and constipation or diarrhea). In the cluster, poor appetite was not included in female group. In females, $13.1 \%$ variance explained by head and GI symptoms (Cronbach's $\alpha=0.699$ ) (Table 5).

\section{Discussion}

The aim of this study was to identify and categorize clustering of symptoms such that if a patient has one somatic symptom, other symptoms in the same cluster may be investigated in order to improve the quality and accuracy of diagnosis a primary care setting. The clustering of some symptoms suggests that when patients have one somatic symptom, other symptoms in the same cluster 
Table 3: Factor loading of varimax rotated factor pattern for 683 subjects

\begin{tabular}{|c|c|c|c|c|}
\hline & \multicolumn{4}{|c|}{ Factor } \\
\hline & $\begin{array}{l}1 \\
\text { Pain } \\
\text { Symptoms }\end{array}$ & $\begin{array}{l}2 \\
\text { Cold Symptoms }\end{array}$ & $\begin{array}{l}3 \\
\text { Cardiopulmonar } \\
\text { y Symptoms }\end{array}$ & $\begin{array}{l}4 \\
\text { Gastrointestinal } \\
\text { Symptoms }\end{array}$ \\
\hline Dizziness & 0.28 & 0.51 & 0.25 & 0.24 \\
\hline Neck pain or stiffness & 0.61 & 0.08 & 0.28 & 0.23 \\
\hline Chest pain & 0.28 & 0.13 & 0.79 & 0.13 \\
\hline Sensation of dyspnea or asphyxia & 0.22 & 0.20 & 0.76 & 0.08 \\
\hline Palpitation & 0.24 & 0.37 & 0.59 & 0.27 \\
\hline Poor appetite & 0.18 & 0.29 & 0.11 & 0.65 \\
\hline Stomach ache or abdominal discomfort & 0.14 & 0.20 & 0.26 & 0.69 \\
\hline Constipation or diarrhea & 0.22 & 0.05 & 0.03 & 0.77 \\
\hline Low back pain & 0.69 & 0.06 & 0.24 & 0.24 \\
\hline Sensation of anesthesia & 0.74 & 0.21 & 0.08 & 0.10 \\
\hline Sensation of heavy limbs & 0.61 & 0.46 & 0.11 & 0.11 \\
\hline Joint pain & 0.72 & 0.23 & 0.12 & 0.06 \\
\hline Muscle weakness & 0.55 & 0.45 & 0.16 & 0.15 \\
\hline Cold sweating & 0.12 & 0.71 & 0.07 & 0.07 \\
\hline Feeling too warm or cold & 0.12 & 0.77 & 0.12 & 0.18 \\
\hline Shuddering & 0.13 & 0.61 & 0.18 & 0.11 \\
\hline Muscle pain & 0.75 & 0.03 & 0.23 & 0.21 \\
\hline$\%$ Variance explained & 20.9 & 15.2 & 11.8 & 11.2 \\
\hline Cumulative variance & 20.9 & 36.1 & 47.9 & 59.1 \\
\hline
\end{tabular}

Factor loadings $\geq 0.50$ are in bold.

should also be evaluated. Based on the factor analysis, we identified 4 clusters of symptoms: Factor 1 was related to pain, Factor 2 was associated with cold-like symptoms, Factor 3 involved symptoms associated with heart and respiration, and Factor 4 was associated with the GI system. The 4 factors categorized 17 out of 22 symptoms. Pain symptoms were the highest in terms of the number of symptoms, percentage of variance explained, and prevalence.

With the exception of differences in a few symptoms, the 4 factors described were comparable to those identified in other foreign and domestic studies [8,9,24]. David et al. [8] classified the common symptoms into 5 major categories, and 3 of them were very similar to the findings in our study. The 3 major categories similar to ours are Category 1, GI symptoms (nausea, vomiting, and abdominal pain); Category 2, pain symptoms (generalized pain, limb pain, back pain, joint pain, dysuria, and headache); and Category 3, cardiopulmonary symptoms (difficulty in breathing, palpitations, chest pain, and dizziness) [8]. Other studies have indicated that females tend to have headache and abdominal pain symptoms with more fre- quency than males $[1,25]$. Our results are consistent with previous studies in that 20 out of 22 symptoms were more prevalent in females, and there was a statistical significance between males and females in 10 out of those 20 symptoms.

With regard to pain symptoms in general, except for headache, individuals older than 65 years experienced more pain symptoms than any other age group. Among the pain symptoms, lower back pain and neck pain and rigidity had the highest prevalence, which is consistent with other studies on seniors [25]. Chest pain was the fifth most common symptom at any age, while other pain symptoms were variously distributed in different age ranges. For example, individuals who were $\geq 45$ years old more commonly experienced hand and foot arthralgia as compared to younger people. On the other hand, individuals who were $<65$ years of age had a greater incidence of muscle pain. Other studies have also indicated that sites of pain were dissimilar between seniors and adults, with seniors having fewer headaches and abdominal pain [2].

Other work indicated dizziness was the third commonly experienced symptom found in a senior primary 
Table 4: Factor loading of varimax rotated factor pattern for $\mathbf{4 3 7}$ males

\begin{tabular}{|c|c|c|c|c|}
\hline & \multicolumn{4}{|c|}{ Factor } \\
\hline & $\begin{array}{l}1 \\
\text { Pain Symptoms }\end{array}$ & $\begin{array}{l}2 \\
\text { Cold } \\
\text { Symptoms }\end{array}$ & $\begin{array}{l}3 \\
\text { Cardiopulmonary } \\
\text { Symptoms }\end{array}$ & $\begin{array}{l}4 \\
\text { Gastrointestinal } \\
\text { Symptoms }\end{array}$ \\
\hline Neck pain or stiffness & 0.61 & -0.16 & 0.22 & 0.44 \\
\hline Chest pain & 0.24 & 0.03 & 0.74 & 0.28 \\
\hline Sensation of dyspnea or asphyxia & 0.22 & 0.13 & 0.70 & 0.17 \\
\hline Palpitation & 0.18 & 0.35 & 0.58 & 0.32 \\
\hline Poor appetite & 0.17 & 0.36 & 0.12 & 0.62 \\
\hline $\begin{array}{l}\text { Stomach ache or } \\
\text { abdominal discomfort }\end{array}$ & 0.15 & 0.14 & 0.14 & 0.76 \\
\hline Constipation or diarrhea & 0.16 & 0.27 & 0.07 & 0.65 \\
\hline Low back pain & 0.65 & -0.04 & 0.23 & 0.32 \\
\hline Sensation of anesthesia & 0.72 & 0.21 & 0.19 & 0.07 \\
\hline Sensation of heavy limbs & 0.55 & 0.45 & 0.24 & 0.04 \\
\hline Joint pain & 0.72 & 0.31 & 0.03 & 0.04 \\
\hline Muscle weakness & 0.53 & 0.48 & 0.29 & 0.07 \\
\hline Clod sweating & 0.09 & 0.59 & 0.19 & 0.23 \\
\hline Feeling too warm or cold & 0.03 & 0.71 & 0.13 & 0.21 \\
\hline Shuddering & 0.23 & 0.63 & 0.09 & 0.13 \\
\hline Muscle pain & 0.74 & 0.11 & 0.17 & 0.22 \\
\hline Frequent micturition & 0.10 & 0.20 & 0.60 & -0.10 \\
\hline$\%$ Variance explained & 19.1 & 13.3 & 12.6 & 12.2 \\
\hline Cumulative variance & 19.1 & 32.4 & 45.0 & 57.1 \\
\hline
\end{tabular}

Factor loadings $\geq 0.50$ are in bold.

care setting [3]. Tsai et al. [9] also found that it was fifth out of the 15 most common symptoms found in seniors $>70$ years old [9]. In our study, it was the fourth most common symptom. According to Furman et al. [4], there were large variations from study to study, ranging from $20 \%$ to $50 \%$; however all revealed a high prevalence [4].

A study of 14 common symptoms in 1000 patients in an internal medicine department found that $38 \%$ of patients had two or more symptoms [5]. A study by Tsai et al. [9] that targeted an elderly population also indicated that $76.49 \%$ of the patients had 2 or more symptoms. In our work, we found that $87.5 \%$ of the patients had two or more symptoms. Some experts have suggested that it is not important to assign a diagnosis of somatoform disorder as long as patient discomforts can be resolved [8]. Furthermore, the combinations of symptoms in this study represent a clustering phenomenon of common symptoms, which may be found in both physical and mental illness.

There are limitations to this study that should be considered. The data are only from a single medical center in central Taiwan, and thus the results may not be applicable to other patient populations. Also, the study did not include a measure for depression and anxiety. That measure was beyond the scope of this work, and we consider this study a preliminary analysis to guide further research. The critical characteristics of frequency and abundance of symptoms were beyond our objective in this study; however, the severity of the disease may affect the structure of clustering, an analysis which should be included in future study.

\section{Conclusions}

We used factor analysis to evaluate 22 common symptoms and created 4 symptom categories seen in primary care patients. The clustering of some somatic symptoms suggests that when patients have one somatic symptom, other symptoms in the same cluster should also be evaluated. We believe this descriptive analysis of common somatic symptoms may provide a reference point for medical personnel to use when evaluating patients with multiple complaints. 
Table 5: Factor loading of varimax rotated factor pattern for $\mathbf{2 4 6}$ females

\begin{tabular}{|c|c|c|c|c|}
\hline & & & Factor & \\
\hline & $\begin{array}{l}1 \\
\text { Pain Symptoms }\end{array}$ & $\begin{array}{l}2 \\
\text { Cold Symptoms }\end{array}$ & $\begin{array}{l}3 \\
\text { Cardiopulmonary Symptoms }\end{array}$ & $\begin{array}{l}4 \\
\text { Head and Gastrointestinal Symptoms }\end{array}$ \\
\hline Dizziness & 0.20 & 0.44 & 0.04 & 0.63 \\
\hline Headache & 0.15 & 0.30 & 0.09 & 0.64 \\
\hline Tinnitus & 0.22 & 0.13 & -0.01 & 0.62 \\
\hline Neck pain or stiffness & 0.57 & 0.16 & 0.25 & 0.30 \\
\hline Chest pain & 0.29 & 0.13 & 0.71 & 0.12 \\
\hline $\begin{array}{l}\text { Sensation of dyspnea } \\
\text { or asphyxia }\end{array}$ & 0.23 & 0.23 & 0.74 & 0.00 \\
\hline Palpitation & 0.23 & 0.24 & 0.58 & 0.39 \\
\hline $\begin{array}{l}\text { Stomach ache or } \\
\text { abdominal discomfort }\end{array}$ & 0.08 & 0.09 & 0.47 & 0.60 \\
\hline Constipation or diarrhea & 0.22 & -0.30 & 0.22 & 0.54 \\
\hline Low back pain & 0.66 & 0.00 & 0.32 & 0.28 \\
\hline Sensation of anesthesia & 0.75 & 0.07 & 0.09 & 0.22 \\
\hline Sensation of heavy limbs & 0.66 & 0.35 & 0.19 & 0.19 \\
\hline Joint pain & 0.64 & 0.01 & 0.36 & 0.21 \\
\hline Muscle weakness & 0.63 & 0.41 & 0.12 & 0.15 \\
\hline Cold sweating & 0.19 & 0.75 & 0.10 & 0.08 \\
\hline Feeling too warm or cold & 0.17 & 0.67 & 0.24 & 0.35 \\
\hline Shuddering & 0.06 & 0.56 & 0.37 & 0.13 \\
\hline Muscle pain & 0.70 & -0.09 & 0.44 & 0.10 \\
\hline Frequent micturition & 0.58 & 0.35 & -0.06 & -0.02 \\
\hline$\%$ Variance explained & 20.1 & 12.2 & 12.7 & 13.1 \\
\hline Cumulative variance & 20.1 & 58.0 & 45.9 & 33.1 \\
\hline
\end{tabular}

Factor loadings $\geq 0.50$ are in bold.

\section{Abbreviations}

DIS-CM: Chinese Revision of the Psychiatric Diagnostic Interview Schedule; DSM-IV: The Diagnostic and Statistical Manual of Mental Disorders; Fourth Edition; OPD: Outpatient Department.

\section{Competing interests}

The author declares that they have no competing interests.

\section{Authors' contributions}

CHT designed the study, participated in data collation, statistical analysis, and writing the draft of the manuscript. The author read and approved the final manuscript.

\section{Acknowledgements}

This study was financially supported by a grant from Cheng Ching Hospital. The authors acknowledge the expert assistance of all colleagues from the health management center of Cheng Ching Hospital.

\section{Author Details}

1Department of Family Medicine, Cheng Ching Hospital, No. 118 sec. 3 ChungKang RD. Taichung 407, Taiwan, ${ }^{2}$ Graduate Institute of Biochemical Sciences and Technology, Chaoyang University of Technology, No.168, Jifong E. Rd., Wufong Township, Taichung County 41349, Taiwan and 3Department of Health Business Administration, HungKuang University, No 34, Chung-Chie Rd, Sha Lu, Taichung, 443, Taiwan
Received: 29 September 2009 Accepted: 10 June 2010 Published: 10 June 2010

\section{References}

1. Crook J, Rideout E, Browne G: The prevalence of pain complaints in a general population. Pain 1984, 18:299-314.

2. Von Korff M, Dworkin SF, Le Resche L, Kruger A: An epidemiologic comparison of pain complaints. Pain 1988, 32:173-1783.

3. Sullivan M, Clark MR, Katon WJ, Fischl M, Russo J, Dobie RA, Voorhees R: Psychiatric and otologic diagnoses in patients complaining of dizziness. Archives of Internal Medicine 1993, 153:1479-1484.

4. Furman JM, Jacob RG: Psychiatric dizziness. Neurology 1997, 48:1161-1166

5. Tinetti ME, Williams CS, Gill TM: Health, functional, and psychological outcomes among older persons with chronic dizziness. Journal of the American Geriatrics Society 2000, 48:417-421.

6. Kroenke K, Mangelsdorff AD: Common symptoms in ambulatory care: incidence, evaluation, therapy, and outcome. The American Journal of Medicine 1989, 86:262-266.

7. Blackwell B, De Morgan NP: The primary care of patients who have bodily concerns. Archives of Family Medicine 1996, 5:457-463.

8. David SS, Kolb NR, Tabas G: Somatizing patient: Part I. Practice diagnosis. American Family Physician 2000, 61:1073-1078. 
9. Tsai CH, Wang C, Lin IH, Wu WC, Chen YC, Lin CD: A study of pain and cardiopulmonary symptoms and their related factors among the elderly. Chinese Journal of Family Medicine 2000, 10:173-181.

10. Wenzel A, Steer RA, Beck AT: Are there any gender differences in frequency of self-reported somatic symptoms of depression? Journal of Affective Disorders 2005, 89:177-181.

11. Stewart RB, Blashfield R, Hale WE, Moore MT, May FE, Marks RG: Correlates of Beck Depression Inventory scores in an ambulatory elderly population: symptoms, diseases, laboratory values, and medications. The Journal of Family Practice 1991, 32:497-502.

12. Bair MJ, Robinson RL, Katon W, Kroenke K: Depression and pain comorbidity. Archives of Internal Medicine 2003, 163:2433-2445.

13. Badger T, Segrin C, Dorros SM, Meek P, Lopez AM: Depression and anxiety in women with breast cancer and their partners. Nursing research 2007, 56:44-53.

14. Kroenke K, Spitzer RL, Williams JB, Linzer M, Hahn SR, deGruy FV, Brody D: Physical symptoms in primary care. Predictors of psychiatric disorders and functional impairment. Archives of Family Medicine 1994, 9:774-779.

15. Mulsant BH, Ganguli M, Seaberg EC: The relationship between self-rated health and depressive symptoms in an epidemiological sample of community-dwelling older adults. Journal of the American Geriatrics Society 1997, 45:954-958.

16. Koenig HG, Cohen HJ, Blazer DG, Krishnan KR, Sibert TE: Profile of depressive symptoms in younger and older medical inpatients with major depression. Journal of the American Geriatrics Society 1993 41:1169-1176.

17. Bridges KW, Goldberg DP: Somatic presentation of DSM III psychiatric disorders in primary care. Journal of Psychosomatic Research 1985, 29:563-569.

18. Waxman HM, McCreary G, Weinrit RM, Carner EA: A comparison of somatic complaints among depressed and non-depressed older persons. Gerontologist 1985, 25:501-507.

19. Rosendal M, Fink P, Bro F, Olesen F: Somatization, heartsink patients, or functional somatic symptoms? Towards a clinical useful classification in primary health care. Scandinavian Journal of Primary Health Care 2005, 23:3-10.

20. Ho TP, Leung PW, Lee CC, Tang CP, Hung SF, Kwong SL, Lucas CP, LiehMak F, Shaffer D: Test-retest reliability of the Chinese version of the Diagnostic Interview Schedule for Children-Version 4 (DISC-IV). Journal of Child Psychology and Psychiatry 2005, 46:1135-1138.

21. American Psychiatric Association: Diagnostic and Statistical Manual of Mental Disorders. 4th edition. Washington, DC: American Psychiatric Association; 1994:551-562

22. Escobar Jl: Pharmacological treatment of somatization/ hypochondriasis. Psychopharmacol Bull 1996, 32:589-597.

23. Escobar Jl, Canino G, Rubio-Stipec M, Bravo M: Somatic symptoms after a natural disaster: a prospective study. The American Journal of Psychiatry 1992, 149:965-967.

24. Coryell W: A blind family history study of Briquet's syndrome. Archives of General Psychiatry 1980, 37:1266-1269.

25. Tinetti ME, Williams CS, Gill TM: Health, functional, and psychological outcomes among older persons with chronic dizziness. Journal of the American Geriatrics Society 2000, 48:417-421.

\section{Pre-publication history}

The pre-publication history for this paper can be accessed here: http://www.biomedcentral.com/1472-6963/10/160/prepub

doi: $10.1186 / 1472-6963-10-160$

Cite this article as: Tsai, Factor analysis of the clustering of common somatic symptoms: a preliminary study BMC Health Services Research 2010, 10:160

\section{Submit your next manuscript to BioMed Central} and take full advantage of:

- Convenient online submission

- Thorough peer review

- No space constraints or color figure charges

- Immediate publication on acceptance

- Inclusion in PubMed, CAS, Scopus and Google Scholar

- Research which is freely available for redistribution

Submit your manuscript at www.biomedcentral.com/submit
C Biomed Central 